\title{
4
}

\section{Implementing e-Governance and e-Government}

\section{Assessment of readiness}

E-governance is a dominant concept that is efficiently driving the implementation of e-government and technology projects around the world. The 'e' in e-governance refers to all aspects of technological implementation in governments throughout Commonwealth countries. The 'e' is also now referred to in multiple ways in the sense that it can refer to e-consultation, e-readiness, e-participation, e-delivery, e-performance or any computations and combinations referring to governance and programme implementation. It is important to stress at the beginning of this chapter that the ways in which e-governance is used are manifold. Implementing an e-programme in a developed country is far different than doing so in a smaller developing country that has limited financial or personnel resources. It is important that all implementation schemes take into account the possibilities and limitations that exist to get programmes up and running. Articulated below are the varying dimensions of e-governance and how the basic principles work for countries at different levels.

Definitions and nomenclature and the application of terms connected to any project being undertaken is important. As was explained above, e-government and e-governance can be defined as two very distinct terms. E-governance is 'a broad topic that deals with the whole spectrum of the relationship and networks within government regarding the usage and application of information and communication technologies (ICTs)', while e-government is 'a narrower discipline dealing with the development of online services to the citizen, more the ' $e$ ' on any particular government service - such as e-tax, e-transportation or e-health' (see chapter 3, above).

Developed countries have the financial and personnel resources to move forward quickly and efficiently in the evolution and implementation of online services. In fact, many countries, during the nascent era of e-government in the early- to mid-1990s implemented programmes that resulted in failures in bringing services online, which cost governments hundreds of millions of dollars. However, countries in the English speaking world, such as the United States, the United Kingdom, Canada and Australia, when confronted with overspends, were able to absorb the losses and move on to develop online services with sufficient funding and the necessary personnel for projects. However, when considering e-government implementation in developing countries a different approach is needed. Essentially, many of these countries have been able to 
turn to donor international organisations and developed countries for finance and personnel resources.

Putting the 'e' on services, such as e-health, e-participation, e-voting, e-environment or e-weather, for example, serves as a guide to the wider subject matter of e-government and e-governance, which can, in time, be imprinted on the public mind. More importantly, the use of terms such as 'e-government', 'e-governance' and 'e-democracy', leads to the creation of an identifiable discipline. This then widens the development of the subject beyond the parameters of government alone and to the larger spheres of civil society, associations, unions, the business community, international organisations and the academic world.

In society, it is the identifying of concepts through words and phrases that leads to cohesion and order. Subject matters create an ambience between stakeholders throughout the society. For example, 'public transportation' or 'environmental issues' are phrases understood by citizens who then relate them in their minds to the mass movements of our times. This is the way e-government must continue to evolve.

In time, technologies will change the way society shapes itself, and this will lead to a widening of the subject matter into new spheres. At that point, a new nomenclature will arise reflecting the change articulated in future generations. However, this new nomenclature will only be an extension of the discipline that began to evolve in the late 20th century. The danger in this time of modernity is the urge to move with the latest 'craze' or 'fad'. It is the job of governments to maintain stability at times of great change, such as those in which we are now living. Part of this stability involves forward thinking while keeping rooted in acceptable principles and processes. Government, governance and democracy have been with us for a long while. By adding the 'e' to these words we maintain a stream of thought and a conceptual framework with which the public can relate. Governments are not in the business of creating fads. Many international organisations have come to accept these terms, and they and other respected thinkers and authors are contributing to this important process of change.

E-government programmes are now 'citizen-centric' in that governments conduct indepth surveys to determine what particular services take first priority. For example, in some countries, such as Canada, an early innovation was the implementation of online filing of tax forms. Over the years this and other online services have proven to be successful across all sectors of society. A 'citizen-centric' approach to e-government recognises that the needs of the citizen come first and will result in successful implementation of online services. In many countries, citizens take for granted the right to go online and engage in information gathering or communication via email or through government websites to public servants. Government websites around the world are now vast information repositories.

\section{Citizen-centric government}

Research looking at the activities of many governments and international organisations around the world indicates that much has been done, and continues to be done, 
to move into this new form of online governance. Governments on the whole are aware of the changing expectations of their citizenry, and of the desire, especially by not-for-profit groups and emerging e-democracy groups, to have a say in the evolution of government policy. How governments deal with this could very well determine future relationships between government and the citizenry. This is a serious governance issue that many governments are now facing. For example, the UK government has evolved extensive e-participation programmes at the national and local level, allowing citizens to engage in dialogue with government departments. This is happening globally, as not only governments but many 'e-democracy' groups have emerged in many countries, developing tools, resources and programmes to involve citizens in the fast growing e-democracy movement worldwide.

E-government continues to be implemented throughout the Commonwealth through a series of important actions. These include political leadership and input of senior public servants, cross-government departmental co-operation, working partnerships with the private sector, especially in the IT sector, and consultation with citizens and groups in society. The latter can be achieved through a number of mechanisms, such as surveys and focus groups, in order to determine what members of the public want in terms of online services.

It must be stressed here that there are vast differences in the implementation of e-government in developed and developing countries. For example, some key elements of success in developed countries are sufficient, experienced and professional personnel equipped with:

- funding;

- resources;

- political support; and

- the ability to build technology infrastructures.

The five points to be implemented to assure the evolution of e-government projects and initiatives in developing countries are:

1. Political approval of funds and resources from a variety of international organisations;

2. Leadership at the top echelons of government to see that e-government projects are implemented;

3. Sufficient financial and personnel resources;

4. Built-in policy issues, such as security, privacy and accountability; and

5. Committees from different levels of government or within departments cooperating to bring the concept e-government to fruition.

The majority of medium-developed and developing countries receive extensive funds to implement e-government projects. International organisations such as the World Bank, the OECD, the British Council, the Canadian International Development Agency 
(CIDA) and the United Nations are just some of the donors. In some instances funding is on a lending basis, though sometimes there are programmes from international organisations providing the necessary funds as outright donations and grants. International organisations also often send experts and consultants to developing countries as advisers for the evolution of IT and e-Government programmes.

An important route to success for developing countries is the development of national IT plans. These are essential to assure success, because they allow for inclusion of all the different aspects of what needs to be done. An 'e-readiness' assessment plan is also crucial if the development of e-government projects is to be successful. For example, one of the first steps to be made when moving forward with IT projects to service the public is to determine the number of households, educational institutes, government agencies and departments, and commercial organisations that have online capacities through which online services can be offered. This will determine the number of services to go online and what funding and personnel are needed. An assessment as to what priority to give each of the services to be implemented must also be made.

An essential point to be made about the evolution of e-government in developing countries is that the circumstances vary from country to country. In many jurisdictions, e-government services would only be available in major cities, because in smaller jurisdictions and towns the necessary infrastructure is not there to bring such services. When there is no Internet connection or facility to hand, mobile phones become the technology of choice to access government services online. Mobile phones have been made available at low cost or as donations in many countries. While this is a solution to gain access to government services, the fact remains that in many poor countries there are too many people that do not have access to these services.

E-governance and e-government are now institutionalised programmes in the majority of countries around the world. There is a large grouping of materials on these subject matters online and in the halls and libraries of governments, universities, NGOs, consulting firms and a host of other groups in society. At the time of writing, only about a sixth of the world's population has some form of online access, even though 94 per cent of countries have some form of online infrastructure. There are many challenges that lie ahead to encompass the poor and disenfranchised of the world. E-governance and its sister groupings can help to bring the information richness of the online world to more and more people. We are at a stage of fundamental change in which the Internet and other new technologies are changing our cultures and the way we live. Our biggest challenge for the future is to encompass more of the citizens of the world in that change.

The following chapters largely report on the context, contents and conclusions of the workshop entitled the Regional Workshop on e-Government Readiness for Effective Public Service Delivery (4-8 June 2007), which was developed by GIDD of the Commonwealth Secretariat, supported by the Government of the Cayman Islands, and was held in Grand Cayman with participation by the countries of the Caribbean and the Mediterranean. 